\title{
Grid to vehicle wireless power supply using single-phase matrix converter
}

\author{
Muhamad Haziq Mohmad Akram, Rahimi Baharom \\ Faculty of Electrical Engineering, Universiti Teknologi MARA, Selangor, Malaysia
}

\begin{tabular}{|c|c|}
\hline Article Info & ABSTRACT \\
\hline Article history: & \multirow{9}{*}{$\begin{array}{l}\text { This paper presents the computer simulation model of a grid to vehicle } \\
\text { (G2V) wireless power supply using a single-phase matrix converter (SPMC). } \\
\text { The proposed system uses the SPMC that operates as a direct AC-AC } \\
\text { converter to convert the supply frequency of } 50 \mathrm{~Hz} \text { to reach } 20 \mathrm{kHz} \text { output } \\
\text { frequency. The use of } 20 \mathrm{kHz} \text { frequency is suitable for wireless power } \\
\text { transfer (WPT) operation in order to obtain higher power transfer efficiency } \\
\text { between the transmitter and the receiver parts. An advanced of the proposed } \\
\text { circuit topology can solve the conventional system for G2V circuit topology } \\
\text { that uses multiple stages of power conversion system, resulting in high power } \\
\text { semiconductor losses that could lead to low efficiency. In this work, multiple } \\
\text { stages of the conventional "AC-DC-AC" circuits have been reduced to a } \\
\text { single power conversion stage by using the SPMC circuit topology. The use } \\
\text { of the proposed circuit topology can reduce the number of devices, thus } \\
\text { reduce the semiconductor losses. A part of reducing the semiconductor } \\
\text { losses, the proposed circuit topology could also improve the power density } \\
\text { and efficiency of the power supply system. A computer simulation model } \\
\text { using MATLAB/Simulink has been developed to investigate the behavior of } \\
\text { the proposed system. Selected simulation results are presented to verify the } \\
\text { functionality of the proposed system. }\end{array}$} \\
\hline Received Aug 28, 2020 & \\
\hline Revised Jan 6, 2021 & \\
\hline Accepted Jan 26, 2021 & \\
\hline Keywords: & \\
\hline $\mathrm{AC}$ to $\mathrm{AC}$ converter & \\
\hline Grid to vehicle & \\
\hline Single phase matrix converter & \\
\hline Wireless power transfer & \\
\hline
\end{tabular}

This is an open access article under the CC BY-SA license.

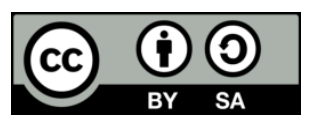

Corresponding Author:

Rahimi Baharom

Faculty of Electrical Engineering

Universiti Teknologi MARA

40450 Shah Alam, Selangor, Malaysia

Email: rahimi6579@gmail.com

\section{INTRODUCTION}

The wireless power transfer technology implies the transfer of electrical energy from a power source to an electrical load through an air gap without the use of any wires or connectors [1]. The most popular high-power wireless power transfer (WPT) is the inductive coupling invented by Nikola Tesla more than a century ago, which refers to the transfer of electrical power through the air [2], [3]. Thus, the removal of the traditional cable connector between the power supply and its load can be convenient for charging millions of devices [4]-[6]. The key components of the WPT system are the transmitter and the receiver coils [2].

The electric vehicle (EV) is a car powered by an electric motor instead of an internal combustion engine, and the engine uses a battery power system [7]. As a future trend, the electric vehicle (EV) has gained more and more interest due to its low or zero carbon emissions and potentially high power output [8], which can be utilized to provide supportive services. With system support for bi-directional transmission of energy between EV and grid, EV can be charged from the grid, referred to as grid to vehicle (G2V) [9]. As EV is discharging and sending electricity to the grid, it is called Vehicle to Grid (V2G) [10], [11]. Similar to the 
V2G concept, where EV will recycle its battery surplus energy back to residential homes for local energy use, named Vehicle to Home (V2H) [12], or back to buildings, called vehicle to building (V2B) [13].

The typical electric vehicle charging system uses a connector cable to connect the electric supply from the grid to the electric vehicle for charging purposes [14]. The disadvantages of a wired connected charging system are the messy wires and safety concerns in the wet environment [15]. The physical requirements of a wired connected charging system present some opportunities for damage. Where mislaid cables may cause tripping hazards. During the rainy season, the water may cause short-circuits through the cables.

In order to solve the limitations or disadvantages of the wired connected charging system, wireless battery charging technologies have been developed [16]. The uses of a wireless charging system can remove expensive and intensive grid cables. Moreover, this technology can also provide additional protection against electrical shock hazards during the charging process [17]. However, the use of wireless charging G2V systems has a disadvantage due to the requirement to use high switching frequency operation to perform an efficient wireless power transfer function. Therefore, the conventional G2V wireless charging system uses "AC-DC-AC" converters to convert low frequency $(50 \mathrm{~Hz}$ or $60 \mathrm{~Hz})$ to the high switching frequency (>20 kHz). The use of multiple stages of power conversion system, resulting in high power semiconductor losses that could lead to low efficiency. In this work, multiple stages of the conventional "AC-DC-AC" circuits have been reduced to a single power conversion circuit by using the SPMC circuit topology. The use of the proposed circuit topology can reduce the number of devices, thus reduce the semiconductor losses. A part of reducing the semiconductor losses, the proposed circuit topology could also improve the power density and efficiency of the power supply system.

Wireless power transfer. Wireless power transfer is a common term for the transmission of energy by means of electromagnetic fields in many different technologies. The wireless power system consists of a "transmitter" device connected to a power source such as a power line that converts the AC power to a timevarying electromagnetic field and a "receiver" device that receives the $\mathrm{AC}$ power.

Conventional wireless G2V circuit topology. Figure 1(a) illustrates the conventional circuit topology of the wireless G2V system. The first conversion stage on the grid side is the AC-DC converter which is used to rectify the line frequency AC voltage to the output DC voltage. The second conversion stage is the DC-AC converter, which is used to convert DC voltage to high-frequency AC voltage to fulfill the requirement of high-efficiency WPT operation. At the receiver side, the high-frequency controllable rectifier is used to charge the battery. Similarly, for Vehicle-to-Grid (V2G), the battery-side converter serves as a highfrequency inverter and the grid-side converters are viewed as a high-frequency, controllable rectifier, and a grid-tied inverter [18].

Single-phase matrix converter. The SPMC requires four bi-directional switches as shown in Figure 1(b). Each bi-directional switch is switchable to conduct current in both directions and to block forward and reverse voltages. Each set of the bi-directional switch is built up by using two IGBTs. Where the source and output of the SPMC can be either single-phase DC or single-phase AC, and rely on the switching strategy to be applied [19]. The feature of the wireless power transfer is that it consists of a transmitter for the high-frequency power transmission and a receiver for the received power [20]. WPT requires a highfrequency switching range from $1 \mathrm{kHz}$ to $100 \mathrm{MHz} .20 \mathrm{kHz}$ of switching frequency has an efficiency of $80 \%$ with the transmitter and the receiver coils of the switching frequency operation [21].

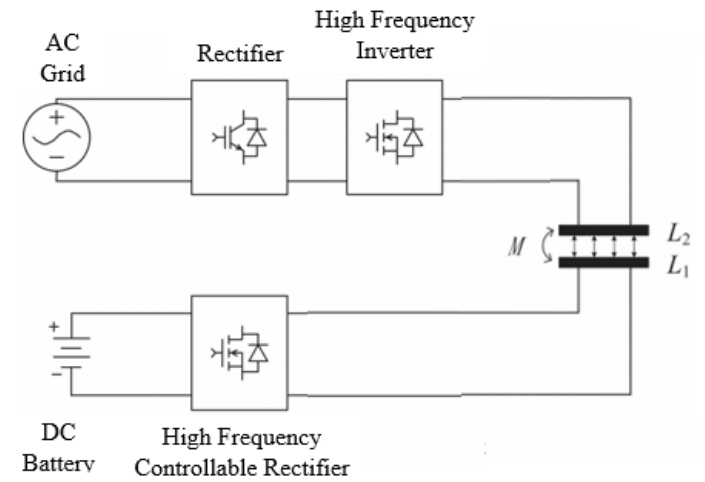

(a)

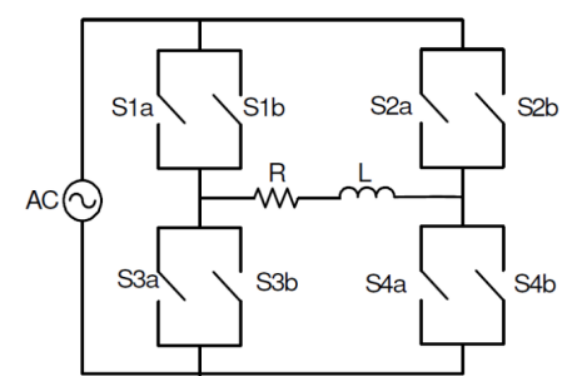

(b)

Figure 1. (a) Conventional circuit topology of G2V, (b) Single phase matrix converter 
Problem statement. Electric vehicles had grown in popularity among users nowadays. The G2V power transmission can be used as a plug-in electric vehicle for charging efficiency. For charging purposes, the cable is required to transfer the power from the grid to the vehicle's battery [14]. Wired connected charging systems had problems with the messy wires that may cause tripping hazards and safety concerns in the wet environment [15]. A much simpler means can be used to simplify the process by transferring the power wirelessly. A system that enables the transmission of electric power without using any connector or wire has been proven reliable.

Apart from that, the conventional circuit of the $\mathrm{G} 2 \mathrm{~V}$ wireless power transfer consists of multiple stages for energy conversion. The first stage is the rectifier to convert the AC input to DC. The next stage is a high-frequency inverter to convert the rectified DC to high-frequency AC. Wireless power transfer needs a high switching frequency to transfer from the transmitter to its receiver. The conventional circuit cannot convert the AC source to high-frequency AC directly. The final stage is to rectify the high-frequency AC from the receiver coil of WPT to the DC form to charge the DC battery of the electric vehicle. While each stage possesses its own losses. Then, with multiple stages, it could lead to high power losses. Thus, requires a new circuit topology to simplify the conventional wireless G2V circuit topology.

\section{RESEARCH METHOD}

Figure 2 shows the flowchart for the proposed system. The proposed G2V wireless power supply begins with the literature review of the $\mathrm{G} 2 \mathrm{~V}$ wireless power supply circuit configurations and the required components. Various types of WPT circuit topologies have been reviewed with highlights their advantages and limitations. Then, the use of SPMC for direct AC to AC converter operation has been investigated. The basic circuit of the AC to AC converter using SPMC was modeled using MATLAB/Simulink software to investigate the behavior of the circuit operation. From the output voltage and current waveforms, it can be used to verify the proposed switching algorithms for AC to AC converter operation using SPMC circuit topology. Then, the proposed G2V wireless power supply using SPMC has been modeled. In order to verify the functionality of the proposed system, the selected simulation results are compared to the theory and hypothesis.

The block diagram of the proposed G2V wireless power supply is as illustrated in Figure 3 . The operation of the proposed system begins from the conversion stage of low frequency to the high-frequency AC voltage. The main part of such a conversion process uses a single SPMC circuit with proper switching algorithms to perform a direct AC to AC converter. The output frequency of the AC to AC converter is $20 \mathrm{kHz}$ that is suitable for wireless power transfer operation [21]. Then, the high-frequency AC voltage at the transmitter side is transmitted wirelessly through the air gap from the transmitter to the receiver coils on the vehicle side. At the vehicle side, the high-frequency AC voltage from the receiver coil is rectified using the full-bridge high-frequency rectifier to convert the AC form to the DC output voltage. The rectified DC output then will be used to charge the DC battery of the vehicle.

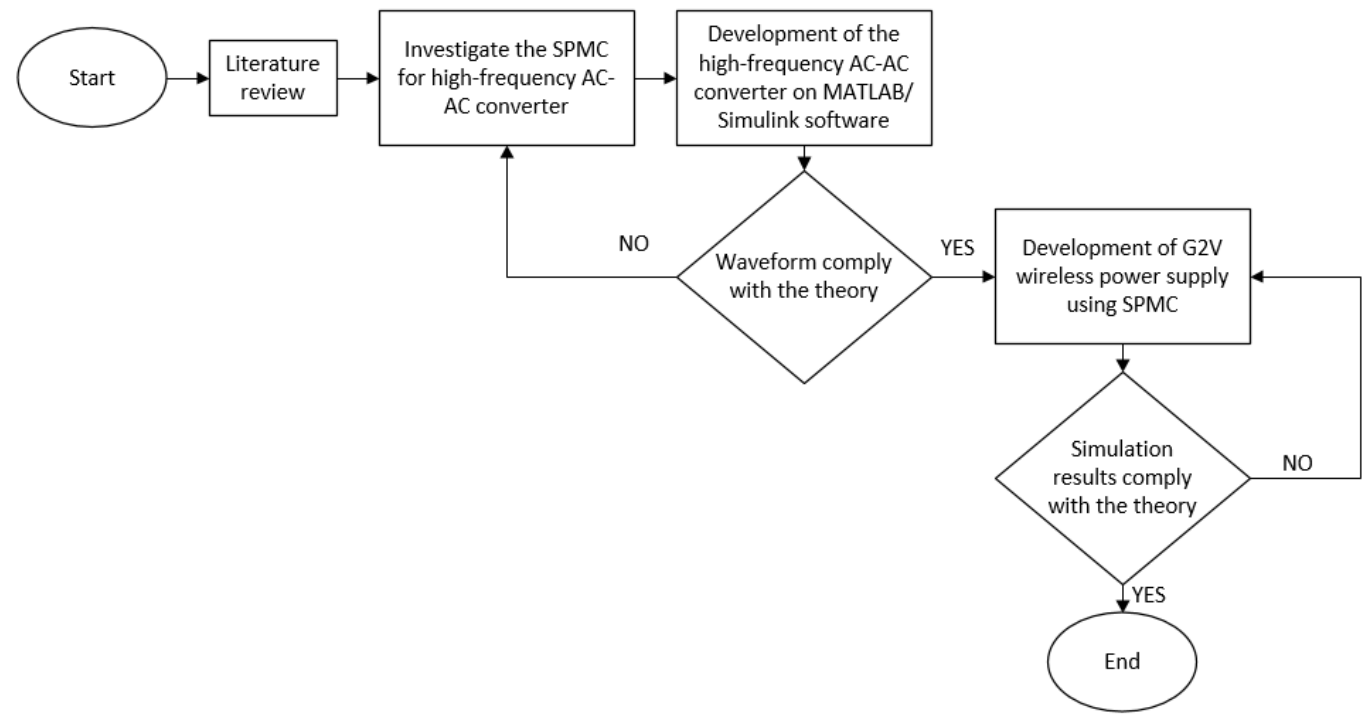

Figure 2. Flowchart of the project 


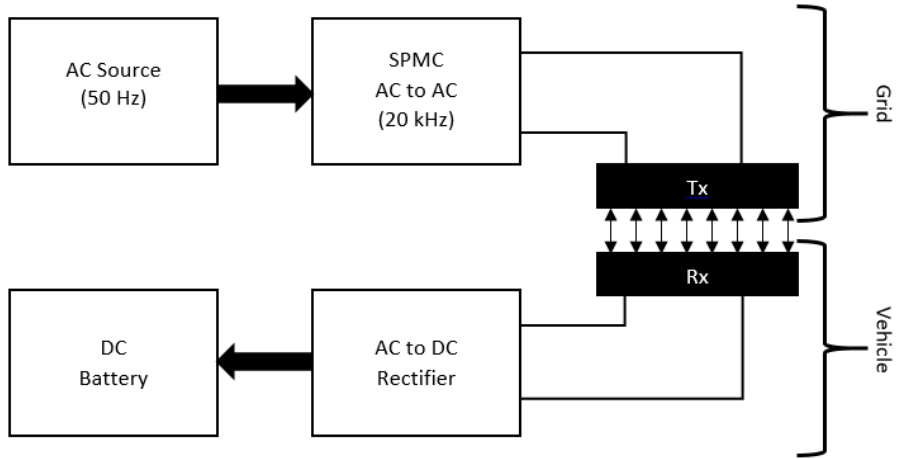

Figure 3. Block diagram of the proposed G2V wireless power supply using SPMC

\section{SWITCHING ALGORITHMS}

The switching algorithms for the proposed system as tabulated in Table 1 can be divided into 4 states. The detailed operation of the proposed circuit is illustrated in Figure 4. The states are as follow [22][24]:

- State 1: During the input positive half cycle and the output positive cycle, both switches S1a and S4a are turning ON, whilst the other switches are turning OFF.

- State 2: During the input negative half cycle and the output negative cycle, both switches S1b and S4b are turning ON, whilst the other switches are turning OFF.

- State 3: During the input positive half cycle and the output negative cycle, both switches S2a and S3a are turning ON, whilst the other switches are turning OFF.

- State 4: During the input negative half cycle and the output positive cycle, both switches S2b and S3b are turning ON, whilst the other switches are turning OFF.

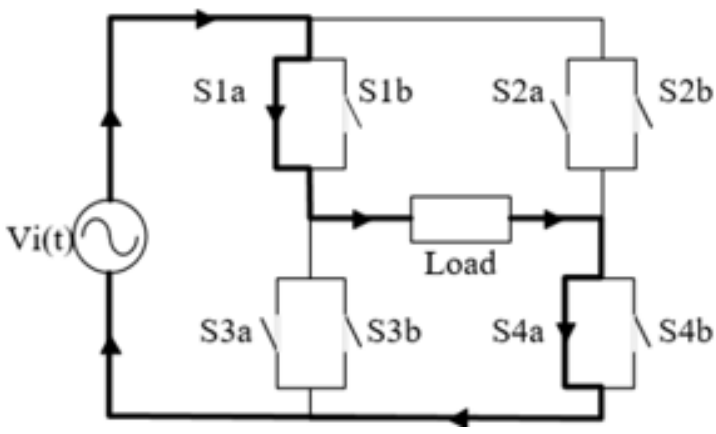

(a)

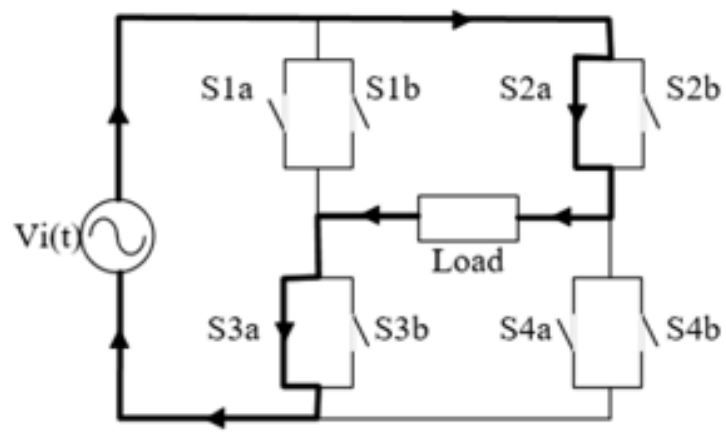

(c)

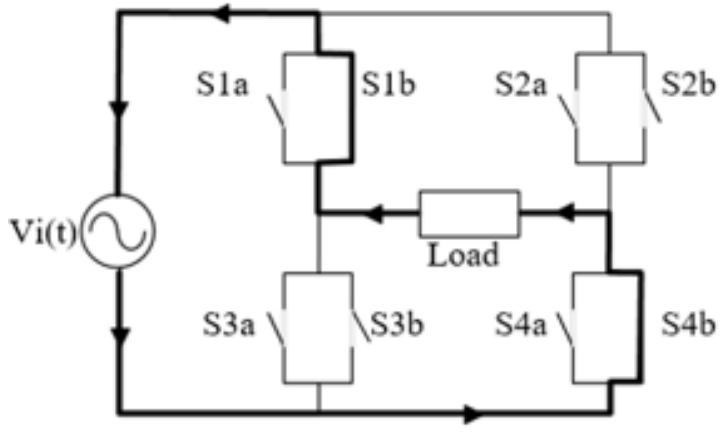

(b)

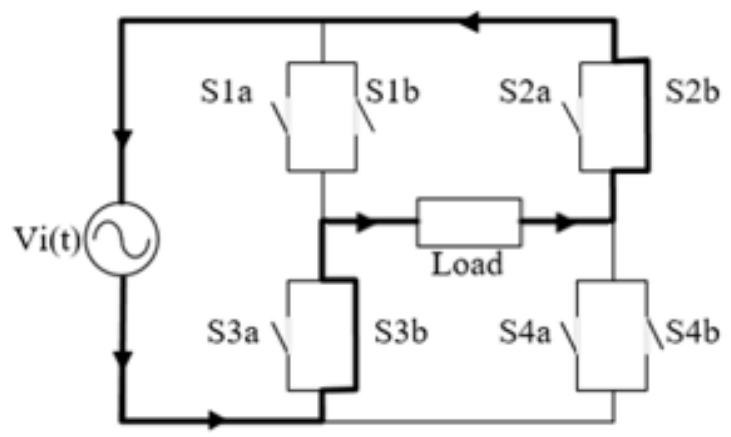

(d)

Figure 4. State of AC-AC switching, (a) State 1 (positive cycle), (b) State 2 (negative cycle), (c) State 3 (positive cycle), (d) State 4 (negative cycle) 
Table 1. SPMC switching control for AC to AC converter

\begin{tabular}{cccc}
\hline Input & Output & State & ON Switch \\
\hline \multirow{2}{*}{ Positive cycle } & Positive & 1 & S1a and S4a \\
& Negative & 3 & S2a and S3a \\
\multirow{2}{*}{ Negative cycle } & Positive & 4 & S2b and S3b \\
& Negative & 2 & S1b and S4b \\
\hline
\end{tabular}

\section{COMPUTER SIMULATION MODEL}

The proposed G2V wireless power transfer using SPMC was simulated using MATLAB/Simulink as shown in Figure 5. This simulation model consists of several block sets such as controller and SPMC. In order to simplify the computer simulation model, the ideal transformer (linear transformer) has been used to act as a wireless power transfer, thus, neglecting any losses that occur during the WPT process. In this work, a bridge of diode has been used as a rectifier with a $2000 \mu \mathrm{F}$ output DC capacitor to reduce the output DC voltage ripple. Then, the $100 \Omega$ resistor is used as a dummy load for the proposed system. Figure 6 (a) shows the simulation model of the SPMC, whilst, the simulation model of bidirectional switches is as shown in Figure 6(b). Such a model consists of two IGBTs and two reverse blocking diodes that are connected in a common emitter and anti-parallel diode pair configuration to perform the required bidirectional switches for SPMC circuit topology. Figure 7 shows the computer simulation model of the switching controller for the proposed system. This controller has been modeled by comparing the sinusoidal waveform using a sine wave block set with the carrier signal (repeating sequence) using a comparator (relational operator) block set to produce the Sinusoidal Pulse Width Modulation (SPWM) signal. During the input positive and output positive cycle, the SPWM signal is compared with the square waveform using the comparator (product1) block for switch S1a and S4a. During the input positive and output negative cycle, the SPWM signal is reversed using a not gate and compared with the square waveform using the comparator (product2) block for switch S2a and S3a. During the input negative and output negative cycle, the SPWM signal is compared with the reversed square waveform using the comparator (product3) block for switch S1b and S4b. During the input negative and output positive cycle, the SPWM signal is reversed using a not gate and compared with a reversed square waveform using the comparator (product4) block for switch S2a and S3a. The SPWM signal for each switch is as shown in Figure 8 and the detail (zoom waveform) is as shown in Figure 9. The parameters used to model the proposed system are as tabulated in Table 2.

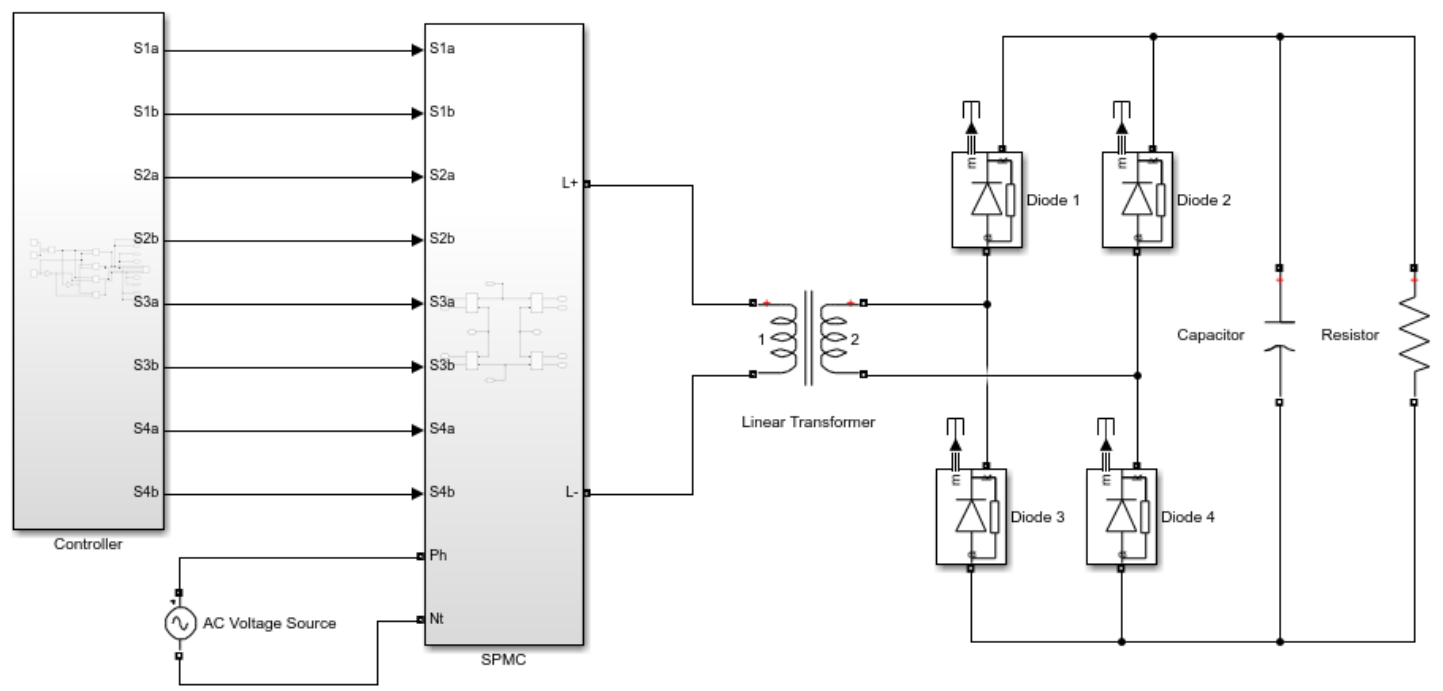

Figure 5. Simulation model of proposed G2V wireless power supply 


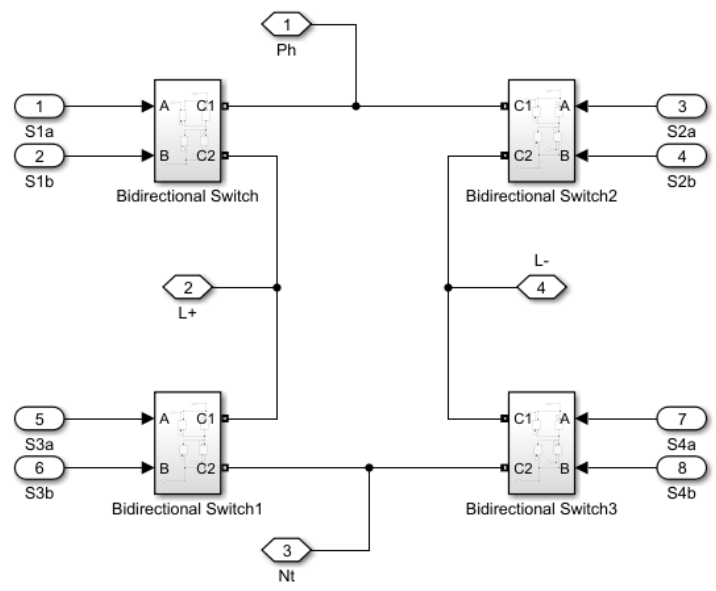

(a)

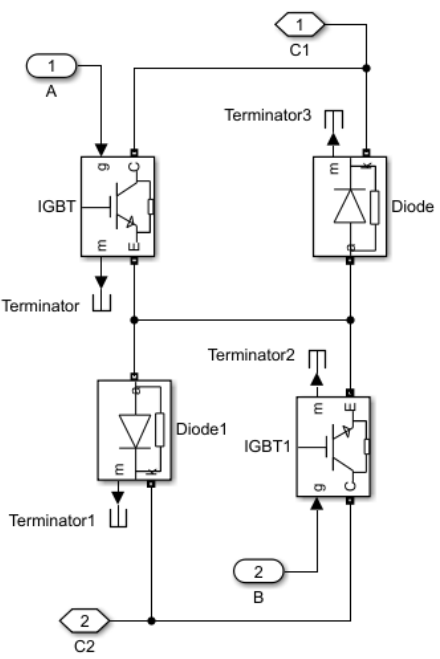

(b)

Figure 6. (a) SPMC simulation model, (b) Simulation model of the bidirectional switch

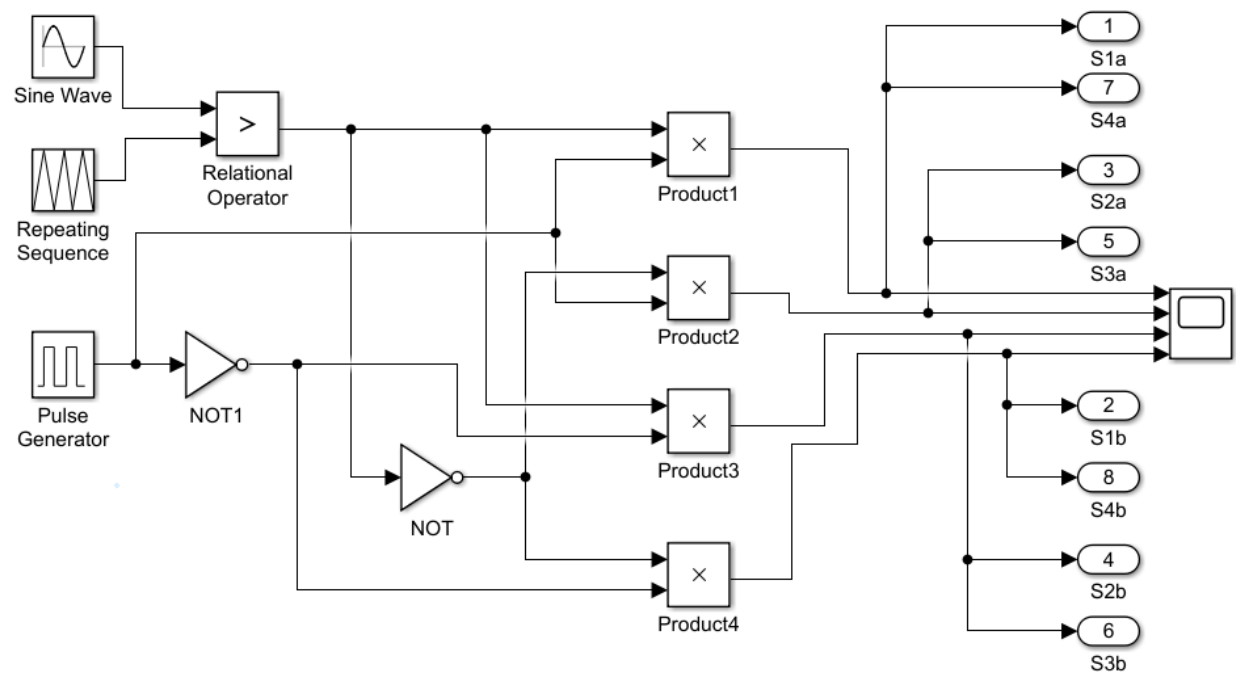

Figure 7. Simulation model of the switching controller

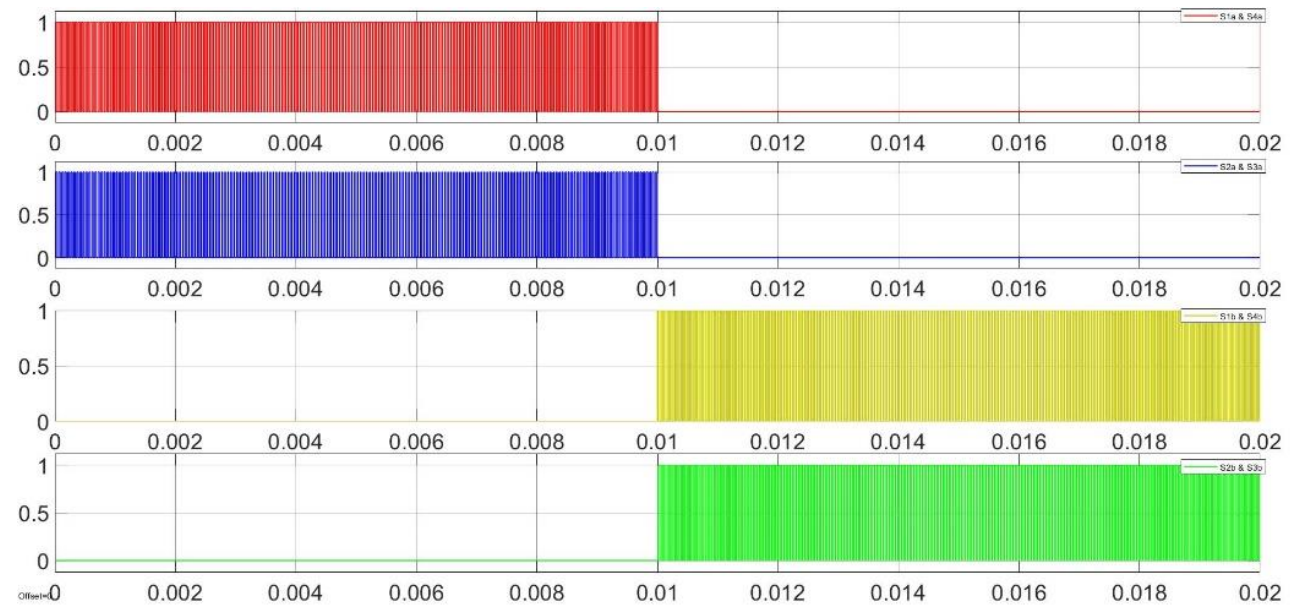

Figure 8. SPWM signal for, (a) S1a \& S4a, (b) S2a \& S3a, (c) S1b \& S4b, (d) S2b \& s3b 


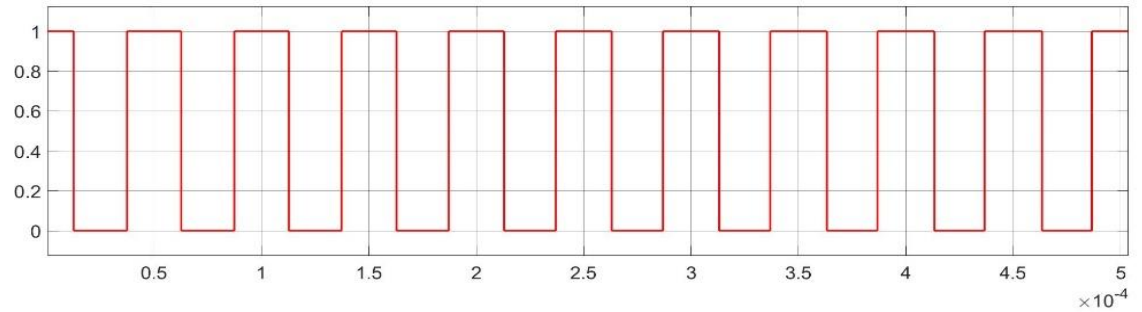

Figure 9. Detail of the SPWM signal

Table 2. The parameters for the simulation model

\begin{tabular}{ll}
\multicolumn{1}{c}{ Parameters } & \multicolumn{1}{c}{ Values } \\
\hline Source voltage & $18 \mathrm{VAC}, 50 \mathrm{~Hz}$ \\
Switching frequency (SPMC) & $20 \mathrm{kHz}$ \\
Resistor & $100 \Omega$ \\
Capacitor & $2000 \mu \mathrm{F}$ \\
\hline
\end{tabular}

\section{RESULTS AND DISCUSSION}

Figure 10(a) shows the input voltage waveform of $18 \mathrm{VAC}$ with $50 \mathrm{~Hz}$ frequency. At the transmitter side of the wireless power transfer, the source voltage of $18 \mathrm{VAC}$ is used as a precaution for the loss due to the converter and transmission before charging the 12 VDC electric vehicle's battery. The source voltage will pass through the SPMC that acts as an AC to AC converter to convert from the line frequency of $50 \mathrm{~Hz}$ to the output high frequency of $20 \mathrm{kHz}$. The use of a $20 \mathrm{kHz}$ switching frequency can provide a high-efficiency wireless power transfer operation [21]. The output high-frequency voltage from the SPMC is as shown in Figure 10(b). With the ideal modulation index of 0.5 , for the $20 \mathrm{kHz}$ SPWM controller, the peak voltage of the SPMC output is $14.4 \mathrm{~V}$ with a reduction of $3.6 \mathrm{~V}$ from the input source voltage. The output from SPMC will be transmitted through wireless power transfer and will be received at the receiver. Because of the use of the ideal transformer as a WPT medium, there are no losses from the WPT process. The voltage waveform at the receiver part is as shown in Figure 11(a). The output of the WPT is then rectified using the full-bridge high-frequency rectifier to produce the DC output voltage form to charge the 12 VDC battery. Figure 11(b) shows the output voltage of the rectifier converter. The output ripple of the load voltage waveform can be determined based on (1) [25]. Thus, the output voltage ripple is $4 \%$, with the average DC output voltage of $12.48 \mathrm{~V}$. The losses that occur due to the rectifier process is $1.92 \mathrm{~V}$ or $13.33 \%$ compared to the received WPT power. The DC output voltage is then used to charge the 12 VDC electric vehicle's battery.

$$
\% \text { ripple }=\frac{V m}{\text { Vave }} \times 100 \%
$$

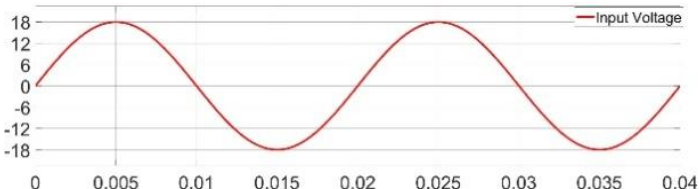

(a)

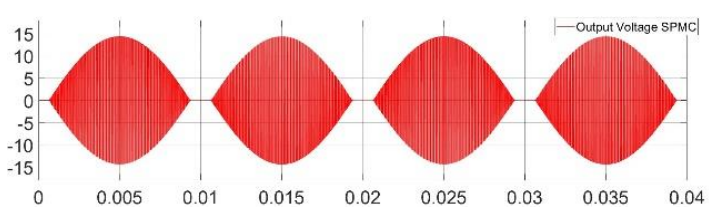

(b)

Figure 10. (a) Source voltage $50 \mathrm{~Hz}$, (b) Output SPMC voltage $20 \mathrm{kHz}$

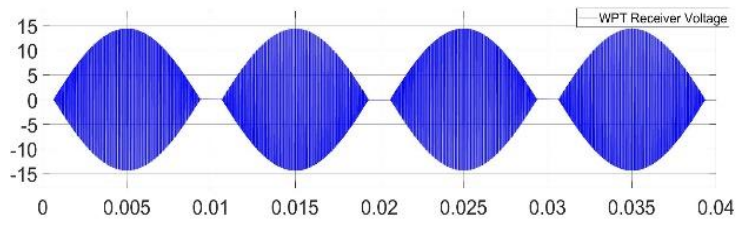

(a)

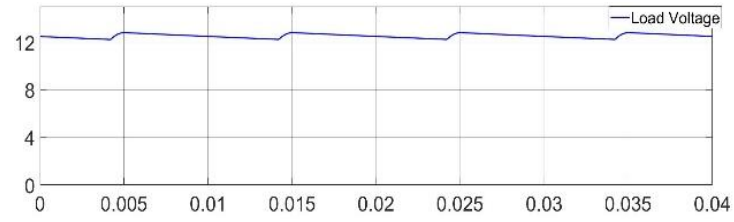

(b)

Figure 11. (a) WPT receiver voltage, (b) Load voltage 


\section{CONCLUSION}

This paper describes the computer simulation model of grid to vehicle (G2V) wireless power supply using a single-phase matrix converter (SPMC). The proposed system had been presented in detail with a simulation model using MATLAB/Simulink. The proposed circuit had simplified the conventional grid to a vehicle circuit with the wireless power transfer function using the SPMC to reduce the losses and circuit complexity of the conventional circuit topology. The use of SPMC in the proposed system can reduce the two conversion stages of the conventional system to a single conversion stage for direct AC-AC converter operation. The value of the output voltage of $12.48 \mathrm{~V}$ and $4.45 \%$ ripple is good enough to charge the commonly used $12 \mathrm{~V}$ battery for an electric vehicle. The advantages of the proposed system such as highpower density and high efficiency can be used as an alternative to the conventional G2V wireless power transfer circuit. The future recommendation for the proposed study is to explore other waveforms for any type of fault in the system because this research only focused on the voltage waveform. Also, since this project only involves simulation, the future study should be on the hardware of the project. This is because of the simulation, and the actual situation may be different due to unexpected factors.

\section{ACKNOWLEDGEMENTS}

Financial support from Research Management Centre (RMC), Universiti Teknologi MARA (UiTM), Grant No. 600-RMC/LESTARI SDG-T 5/3 (188/2019) is gratefully acknowledged.

\section{REFERENCES}

[1] A. Gil and J. Taiber, "A Literature Review in Dynamic Wireless Power Transfer for Electric Vehicles: Technology and Infrastructure Integration Challenges," Sustainable Automotive Technologies, pp. 289-298, 2013.

[2] M. Q. I. M. Zamani, R. Baharom, and D. Johari, "Conceptual study on grid-to-vehicle (G2V) wireless power transfer using single-phase matrix converter," International Journal of Power Electronics and Drive System (IJPEDS), vol. 10, no. 3, pp. 1382-1388, 2019.

[3] M. P. Kesler, "Highly Resonant Wireless Power Transfer: Safe, Efficient, and over Distance," 2017. https://witricity.com/wp-content/uploads/2016/12/White_Paper_20161218.pdf.

[4] B. Yang, S. Du, W. Chen, C. Deng, and D. Xu, "Optimal parameter design for series-series resonance converter for wireless power transfer," 2014 International Power Electronics and Application Conference and Exposition, 2014, pp. 772-777.

[5] G. W. M. S. C. Moon, "Wireless power transfer system with asymmetric 4-coil resonator for electric vehicle battery charger," 2015 IEEE Appl. Power Electron. Conf. Expo, 2015, vol. 31, no. 10, pp. 1650-1657.

[6] M. Etemadrezaei, "Wireless Power Transfer," in Power Electronic Handbook, Science Direct, pp. 711-722, 2018.

[7] B. Frieske, M. Kloetzke, and F. Mauser, "Trends in Vehicle Concept and Key Technology Development for Hybrid and Battery Electric Vehicles," World Electric Vehicle Journal, vol. 6, pp. 9-20, 2013.

[8] Yao Y., Gao W., and Li Y., "Optimization of PHEV Charging Schedule for Load Peak Shaving," IEEE Conference and Exposition on Transportation Electrification, 2014, pp. 1-6.

[9] Hua L., Wang J., and Zhou C., "Adaptive Electric Vehicle Charging Coordination on Distribution Network," IEEE Transactions On Smart Grid, vol. 5, no. 6, p. 2666-2675, 2014.

[10] Hosseini S., Badri A., and Parvania M., "The Plug-in Electric Vehicles for Power System Applications: The Vehicle to Grid (V2G) Concept," 2012 IEEE International Energy Conference and Exhibition (ENERGYCON), 2012, pp. 1101-1106.

[11] Donoghue J. and Cruden A., "Whole System Modelling of V2G Power Network Control, Communications and Management," 2013 World Electric Vehicle Symposium and Exhibition (EVS27), 2013, pp. 1-9.

[12] Zhao L. and Aravinthan V., "Strategies of Residential Peak Shaving With Integration of Demand Response and V2H," IEEE PES Asia-Pacific Power and Energy Engineering Conference (APPEEC), 2013, pp. 1-5.

[13] S. H. S. S. Saberbaril E., "Utilizing PREYs for Peak-Shaving, Loss Reduction and Voltage Profile Improvement via V2B Mode," The 19th Electrical Power Distribution Conference (EPDC2014), 2014, pp. 59-65.

[14] D. Jung, Y. Ji, C. Won, T. Lee, S. Lee, K. Seo, "Grid-Connected Electric Vehicles Charger Station Based on Lithium Polymer Battery Energy Storage System," 2010 IEEE Vehicle Power and Propulsion Conference, 2010, pp. $1-5$.

[15] K. N. Mude, "Battery Charging Method for Electric Vehicles: From Wired to On-Road Wireless Charging," Chinese Journal of Electrical Engineering, vol. 4, no. 4, pp. 1-15, 2018.

[16] C. Qiu, K. T. Chau, C. Liu, and C. C. Chan, "Overview of Wireless Power Transfer for Electric Vehicle Charging," International Battery, Hybrid and Fuel Cell Electric Vehicle Symposium, 2013.

[17] M. Hassan and A. E. Zawawi, "Wireless power transfer (Wireless lighting)," 2015 5th International Conference on Information \& Communication Technology and Accessibility (ICTA), 2015, pp. 1-4.

[18] Z. Sun, Q. Chen, L. Zhang, and R. Long, "Research on Bidirectional Wireless Power Transfer System for Electric Vehicles," $201934^{\text {th }}$ Youth Academic Annual Conference of Chinese Association of Automation (YAC), vol. 4, no. 19, pp. 468-472, 2019.

[19] D. Ahirrao, B. Gaware, P. Kakade, and P. Kharade, “Analysis of Single Phase Matrix Converter," Int. Journal of Engineering Research and Applications, vol. 4, no. 3, pp. 856-861, 2014.

Grid to vehicle $(G 2 \mathrm{~V})$ wireless power supply using single-phase matrix ... (Muhamad Haziq Mohmad Akram) 
[20] P. N. A. M. Yunus, A. Jusoh, and M. K. Hamzah, "Passive Damping Network for a Single Phase Matrix Converter (SPMC) Operating As a Rectifier," Symposium on Industrial Electronics and Applications, vol. 7, no. 11, pp. 173-177, 2011.

[21] D. Alashgar, K. Fujiwara, and N. Nagaoka, "Fundamental Investigation of Short-Range Inductive Coupling Wireless Power Transmission by Using Series-Series Capacitive Compensation Topology," Journal of Asian Electric Vehicles, vol. 17, no. 1, 2019.

[22] S. Z. M. Noor, N. F. A. Rahman, and A. M. Aris, "Modeling and Simulation of a Single-Phase Boost AC-AC Converter Using Single-Phase Matrix Converter Topology," International Conference on Computer Applications and Industrial Electronics, pp. 208-213, 2011.

[23] S. Subha, "Realization of AC-AC Converter Using Matrix Converter," World Applied Sciences Journal, vol. 9 , no. 29, pp. 1117-1122, 2014.

[24] Z. Zainuddin, R. Baharom, I. M. Yassin, and K. S. Muhammad, "Solid-State Transformer (S2T) of Single Phase Matrix Converter," International Journal of Power Electronics and Drive System (IJPEDS), vol. 9, no. 3, pp. 997$1005,2018$.

[25] I. S. A. Razak, R. I. Z. R. Z. Hashima, and S. N. M. Soid, "A Design of Single Phase Bridge Full-wave Rectifier," Conference on Language, Education, Engineering and Technology, 2016, vol. 2. 